\title{
Hispanic culture and healthcare in the United States: One person's perspective
}

\author{
Melanie Julia Johnson*, Hope Rosemarie Farquharson
}

Citation: Johnson MJ, Farquharson HR. Hispanic culture and healthcare in the United States: One person's perspective. J Nur Res Prac. 2019; 3(4):01-02.

Culturally competent care in the United States? There are approximately 60.4 million people of Hispanic origin living the United States today. This population is the largest minority population in our country and many healthcare providers will come in contact with persons of this culture when providing care. This population is rich in tradition and religious foundation often guiding healthcare beliefs and health practices in the home. Cultural beliefs and religious affiliation, in conjunction with barriers to healthcare such as lack of access to care, healthcare provider unfamiliarity with the culture, perception of care, and language are all factors that deter people of this culture from getting medical help and attention when needed. The purpose of this article is to familiarize the reader with some common beliefs and traditions in the Hispanic culture as seen through the eyes of a person of this culture and to fortify the need for all healthcare providers and nurses in the U.S. to become culturally competent not only with the Hispanic culture, but all the cultures they provide care for. Culturally competent providers can break down barriers to healthcare by providing education, a more comfortable and accessible environment for the Hispanic client thus changing their perception of that care in the future with an optimal goal of decreasing incidences of chronic illness and improving health outcomes.

Keywords: Hispanic; Culture; Access to care; Nursing; Healthcare provider; Beliefs; Culturally competent care; Barriers; Diabetes; Health outcomes

\section{INTRODUCTION}

The Hispanic culture is rich in tradition and religious foundation. There are approximately 60.4 million people of Hispanic origin living in the United States (U.S.) today encompassing the largest minority population in our country US Census Bureau [1]. The U.S., bordering Mexico, is rich in citizens belonging to the Hispanic culture especially the southern border states of California, Arizona, New Mexico, and Texas. Nurses and healthcare workers come in contact with people of different cultures daily and must be cognizant of their beliefs, practices, and traditions in order to provide well-rounded care at all times. In an article by Cersosimo and Musi [2], the Hispanic population is at risk for several healthcare conditions such as diabetes. Further, the article states cultural and socioeconomic factors have been cited to contribute to an increase in health conditions like diabetes. These factors include: Reduced access to healthcare, language barriers, cultural beliefs, and lack of cultural competence by the healthcare provider. These factors can negatively impact how people of any culture perceives approach to healthcare and may cause a dissatisfaction with that care, or cause the person of that culture not to seek out the care they need Cersosimo and Musi [2]. Lack of healthcare in the hispanic population or a negative perception of that healthcare can put the population at greater risk for ability to detect illness later in life [3]. According to the article, "Guidelines for Implementing Culturally Competent Nursing Care" by Douglas et al. [4], "Nurses shall gain an understanding of the perspectives, traditions, values, and family systems of the culturally diverse populations for whom they provide care." It is very important that healthcare providers, not only from the specific states mentioned previously, but from all states in the U.S., be aware of the various beliefs and practices relating to the Hispanic culture and how these practices may influence how people of this culture react to healthcare providers and healthcare in general. By familiarizing themselves with basic cultural beliefs and practices of various cultures, nurses and healthcare providers will provide a more well-rounded approach to care whereby making the client of that culture more apt to continue to seek out care when needed.

\section{PURPOSE}

The purpose of this paper is to familiarize the reader to some basic cultural practices and beliefs in the Hispanic culture as they apply to healthcare in the United States and also speak to healthcare and culture from the perspective of a member of that specific population. An interview was conducted with a client from the Hispanic population and information from that interview is revealed within the body of this work. The client that was interviewed for this commentary has agreed to be referred to as "Alicia."

\section{LITERATURE REVIEW - A CASE SCENARIO}

Alicia is a 40-year old female living in the border city of El Paso, Texas. This is the city of her birth and she has many immediate and extended family members in the city, outlying towns, and across the border in Juarez, Mexico. Alicia speaks English as well as Spanish, is married to a Caucasian male in the U.S. Armed Forces, and has three children, all girls, ages ten years and eight year old twins. Her mother and father live within of block of her home and a sister and a brother live within a few miles of her home. She has a degree in education but does not work in that field at this time. She is a stayat-home mother. Her religious affiliation is that of the Catholic faith as is the main religion for most people of this culture [5]. She admits to being a more "Americanized" member of her family but adopts many beliefs and traditions of the older, more traditional members of her family.

\section{Family dynamics and healthcare}

The value placed on human life is paramount in the Hispanic culture. Alicia feels that the "closeness" in a Hispanic family is very different from that in an American family as she compares her husbands' family values and cultures to her own. She states her husbands' family is not close knit and all family members live very far from each other and do not visit often. Human life is valued across the age continuum Alicia states, with an emphasis on the elderly population. Elderly members of the family group are treated with respect often living in the same household as their children, grandchildren and other extended family National Hispanic Council on Aging [6]. She further states that the culture takes care of the older members of the family in the home instead of placing them in "old folks homes."

Healthcare and approach to healthcare can vary among different cultures and groups. Alicia states that many members of her family, especially the elder generation, prefer seeing a male physician because male doctors are considered more knowledgeable than that of their female counterparts. Additionally, she states that Hispanic women are generally very shy when it comes to discussing medical information with providers or when undergoing exams that require exposure of the breasts and genital areas. It is important to note that healthcare providers in the U.S. take privacy during medical exams

Department of Nursing, College of Professional Studies, National University, San Diego, CA, USA

Correspondence: Melanie Julia Johnson, Assistant Professor, Department of Nursing, College of Professional Studies, National University, San Diego, CA, 92123, USA, e-mail: mjohnson4@nu.edu

Received: November 22, 2019, Accepted: December 24, 2019, Published: December 31, 2019

open $\odot$ ACcess

This open-access article is distributed under the terms of the Creative Commons Attribution Non-Commercial License (CC BY-NC) (http:// creativecommons.org/licenses/by-nc/4.0/), which permits reuse, distribution and reproduction of the article, provided that the original work is properly cited and the reuse is restricted to noncommercial purposes. For commercial reuse, contact reprints@pulsus.com 
very seriously for people of any culture and that every patient is protected by the Health Insurance Portability and Accountability Act (HIPPA) to ensure that privacy [7]. Providers must maintain that privacy with every patient, regardless of ethnicity, culture, or creed so individuals and families can feel more comfortable sharing information with their physicians, nurses, and other providers.

\section{Cultural beliefs and religion}

The Hispanic culture revolves around various religious beliefs predominantly that of the Catholic faith [5]. In many Hispanic homes, one will find religious statues, saints and crucifixes to represent their religious affiliation. People of this culture commonly rely on their faith through prayer for healing of loved ones and for those who have died. Many families keep make-shift alters in the home with a beloved statue of a saint or the Virgin Mary to pray to as in the case of a family member of Alicia's who had just given birth to a still born infant just weeks prior to her interview for this work. To protect the soul of the stillborn infant, the mother gave offerings in the form of diapers, baby formula and rattles to a statue of a Catholic saint placed on an in-home alter [8]. Alicia states that her culture feels that, "God will take you when it is your time" therefore, death is accepted when it comes and the use of lifesustaining equipment in many cases is frowned upon.

\section{Cultural beliefs and folk healing}

The use of healing remedies and requesting the aid of "healers" also known as couranderos in the Hispanic culture is common [9]. Due to reduced access to care, language barriers, and lack of familiarity of American culture many Hispanics move to self-healing or seek out healers within their own cultural groups $[3,9]$. Alicia states that these lay healers, usually of the Catholic faith, are used to heal many illnesses within the household or community and that members of her family in Mexico have used the services of these healers for such ailments such as sore throats, depression, pain in childbirth, and other illnesses. In Trotter and Chavira's work [9], Couranderos (male) or Couranderas (female) are men or women healers who incorporate folkmedicine into their remedies using such things as plants, oils, eggs, amulets, and various herbs to cure and treat. Preventative healthcare, Alicia states, is not usually practiced in this culture as many are uncomfortable going to get care or cannot get access to that care. The National Healthcare Quality and Disparities Report [10], found that race and ethnicity were the second and third leading indicators, after lack of insurance, in determining which Americans were unable to receive or experienced delays in receiving necessary health care, medication or dental care.

\section{Healthcare management and health risks}

The family plays an important role in the delivery of healthcare and healthcare management to each member in the group. Great emphasis is placed on religious beliefs in the maintenance of health and the treatment of illness. Home remedies, along with "lay healers" are also an integral part of the healthcare regimen for families in this culture. In addition, diet and exercise do not have a prominent place in the daily activities of the Hispanic family. As a result of these cultural findings, along with factors such as genetic predisposal, and access to care, Hispanics have a high rate of diabetes, hypertension, and obesity [3]. In caring for patients of this culture, emphasis must be placed on the importance of a balanced diet and daily exercise to minimize risk of such diseases and conditions [3]. Interprofessional collaboration, along with education, may assist with reducing health disparities in the Hispanic population because it brings a comprehensive team of healthcare providers together to treat the patient and family. This comprehensive team-based approach can provide extensive expertise to the community that would otherwise not be present; thus, providing additional resources, health care services, and the potential for unexpected positive outcomes for that community [11,12].

\section{DISCUSSION AND CONCLUSION}

In conclusion, healthcare providers must remain steadfast in learning more about different cultures, beliefs, and practices to show each patient and family that they are dedicated to culturally appropriate care, not only from a physiological perspective, but also from a cultural and psychosocial perspective. Listening and observation skills are very important tools to use in the assessment of the Hispanic patient and aids in developing an important rapport with the patient and family to allow for open channels when teaching and caring for the hispanic family. This is a multi-cultural world and continuous study of those cultures by healthcare providers should be maintained in order to provide comfortable, prudent and confident healthcare to different populations. Is it enough just to be familiar with cultural beliefs and practices among various populations as healthcare providers or can we do more?

According to the National Healthcare Quality and Disparities Report from 2000 through 2016-2017, disparities persist, especially for poor and uninsured populations in all priority areas. Hispanics received worse care than Whites for about $35 \%$ of quality measures which were defined as access to care and quality of healthcare. As researchers continue to study various cultures and become more knowledgeable about their healthcare practices in efforts to decrease incidence of chronic illness especially diabetes, hypertension and obesity, one must find ways to break through the barriers, promote preventative interventions, and provide prudent care and education to bridge the disparity that exists among many minority cultures such as the Hispanic culture.

\section{REFERENCES}

1. US Census Bureau. United States: Quick Facts: 2018. Retrieved from http://www.census.gov

2. Cersosimo E, Musi, N. Improving Treatment in Hispanic/Latino Patients. The American Journal of Medicine. 2011;10: S16-21. Retrieved from https://www-sciencedirect-com.nuls.idm.oclc.org/science/article/ abs/ pii/S0002934311006267

3. Juckett G. Caring for Latino patients. American Family Physician. 2013;87: 48-54. Retrieved from https://www.aafp.org/afp/2013/0101/ p48.html

4. Douglas M, Rosenkoetter M, Dula P, et al. Guidelines for Implementing Culturally Competent Nursing Care. Journal of Transcultural Nursing. 2014;25: 109-121. Retrieved from https://journals-sagepub-com.nuls. idm.oclc.org/doi/ full/10.1177/1043659614520998

5. Schmidt K. How Do I Best Provide Spiritual Care to Hispanic Patients? Journal of Christian Nursing. 2019;36: p.125. Retrieved from https:// www.ovidsp-dc2-ovid-com.nuls.idm.oclc.org

6. Yanira Cruz. Hispanic Family Caregiving: Proceedings from a Thought Leaders Roundtable. National Hispanic Council on Aging. 2017. Retrieved from http://www.nhcoa.org/wp-content/uploads/2017/04/ Final-Proceedings-Caregiving-Thought-Leaders-Roundtable-WashingtonDC-1.pdf

7. US Department of Health and Human Services. Health Information Privacy. 2019. Retrieved from https://www.hhs.gov/hipaa/forindividuals/guidance-materials-for-consumers/index.html

8. Pew Research Center. The Shifting Religious Identity of Latinos in the United. 2014. Retrieved from https://search-proquest-com.nuls.idm. oclc.org/docview/1523091825

9. Sanchez A, Trotter, Chavira's. An examination of the folk healing practice of Curanderismo in the Hispanic Community. Journal of Community Health Nursing. 2018;35: 148-161. Retrieved from http:// www.doi.org.nuls.idm.oclc.org/10.1080/07370016.2018.1475801

10. Agency for Healthcare Research and Quality. National Healthcare Quality and Disparities Report. 2018. Retrieved from https://www. ahrq.gov/research/findings/nhqrdr/nhqdr18/index.html

11. Vanderbilt A, Dail MD, Jaberi P. Reducing health disparities in underserved communities via interprofessional collaboration across healthcare professions. Journal of Multidisciplinary Healthcare. 2015; 8: 205-208. Retrieved from https://www.ncbi.nlm.nih.gov/pmc/articles/ PMC4411015

12. Fitzgerald E, Cronin S, Boccella S. Anguish, yearning, and identity: Toward a better understanding of the pregnant Hispanic woman's prenatal care experience. Journal of Transcultural Nursing. 2015;27: 464-470. Retrieved from https://www.journals.sagepub.com/doi/ full/10.1177/1043659615578718 